Ensino, Saúde e Ambiente - V4 (2), pp. 28.44, ago. 2011

\title{
COMO ENSINAR TEORIAS COGNITIVAS NUM CURSO DE MESTRADO PROFISSIONAL EM EDUCAÇÃO MATEMÁTICA - UMA EXPERIÊNCIA COM MESTRANDOS
}

\section{HOW TO TEACH COGNITIVE THEORIES IN A PROFESSIONAL MASTER'S COURSE IN MATHEMATICAL EDUCATION - AN EXPERIENCE WITH MASTER'S STUDENTS}

\author{
Gabriela dos Santos Barbosa \\ Programa de Mestrado Profissional em Educação Matemática da Universidade Severino Sombra \\ Departamento de Educação Matemática da Faculdade de Educação da Baixada Fluminense / \\ Universidade do Estado do Rio de Janeiro. gabrielasb80@ hotmail.com
}

\begin{abstract}
RESUMO
Este artigo relata uma experiência realizada com alunos do curso de Mestrado Profissional em Educação Matemática da Universidade Severino Sombra, Vassouras, Rio de Janeiro. A experiência é parte de uma sequência de atividades mais ampla utilizada para investigar por que e como teorias cognitivas devem ser abordadas nesse nível de ensino. Descrevemos a reflexão estabelecida com os alunos sobre as principais ideias da Teoria dos Campos Conceituais com base na análise das soluções que eles apresentaram para um problema matemático que envolve o conceito de função afim. Partimos do princípio de que o estudo das teorias cognitivas na formação inicial ou continuada do professor só faz sentido se favorecer a compreensão do processo de aprendizagem da Matemática. Concluímos que a metacognição, isto é, o esforço para compreender o próprio processo de aprendizagem e o resgate de suas experiências como professores contribuíram significativamente para que os alunos se apropriassem das teorias.
\end{abstract}

Palavras-chave: teorias cognitivas, aprendizagem matemática, mestrado profissional, teoria dos campos conceituais.

\begin{abstract}
This article makes an account of the experience carried out with students of Professional Master's Course in Mathematical Education of the SeverinoSombra University, situated in Vassouras, Rio de Janeiro. The experience is part of a broader sequence of activities used to investigate why and how cognitive theories should be approached in this teaching level. We describe a reflection established with students about the Conceptual Field Theories'main ideas, based on the analysis of the solutions they present for a problem that involves the concept of first degree function. We depart from the principle that the study of cognitive theories in teachers' initial or continuous formationonly makes sense if it enhances the Mathematical learning process. We conclude that metacognition, that is, the effort to understand one's own learning process and the recovery of one's own experiences contributed significantly for students' appropriation of the theories.
\end{abstract}

Key-words: cognitive theories, math learning, professional master's course, conceptual field theory. 


\section{INTRODUÇÃO}

$\mathrm{O}$ ponto de partida para as atividades que originaram este artigo foi a pergunta "Como ensinar teorias cognitivas num curso de mestrado profissional em Educação Matemática?". Na tentativa de respondê-la, surgiram várias possibilidades e também foram relembrados vários obstáculos com os quais as disciplinas pedagógicas, entre elas a Psicologia Educacional, se deparam nos cursos de Licenciatura em Matemática. A resposta a essa questão é extremamente complexa, pois decorre de fatores inerentes ao estudante (seus interesses de pesquisa e seus conhecimentos anteriores sobre esse assunto), ao professor (sua área de atuação e suas referências sobre métodos de ensino), ao programa de mestrado como um todo (suas linhas de pesquisa, as possibilidades de articulação das teorias cognitivas com estas linhas e com as demais disciplinas oferecidas pelo programa) e muitos outros que influenciam o que vai ser ensinado.

A versão provisória das Diretrizes Curriculares para Cursos de Licenciatura em Matemática, publicada pelo Ministério da Educação e Cultura (MEC) em junho de 1999, refere-se aos saberes profissionais necessários à docência e destaca a necessidade de articulação entre conteúdos e metodologias. Em resumo, este documento propõe, entre outras coisas, a associação entre os conteúdos matemáticos e seus possíveis tratamentos didáticos nos cursos de formação docente. Desde então, intensificaram-se os processos de re-organização curricular dos cursos de Licenciatura em Matemática em todo território nacional. As chamadas por Moreira e David (2010) disciplinas integradoras foram criadas para efetivar tal articulação (Didática da Matemática, Prática de Ensino da Matemática etc.) e, em alguns casos, novas metodologias foram incorporadas às disciplinas específicas como Cálculo Diferencial e Álgebra Linear de modo que fosse possível aos licenciandos perceber as contribuições do estudo destes assuntos para sua atividade profissional futura e refletir sobre o ensino de temas centrais como funções e matrizes.

No entanto, efetivar estas transformações não foi nem é uma tarefa simples. Falta ao professor do nível superior formação adequada para, de fato, em suas aulas, articular conteúdos e metodologias. Além disso, com o enxugamento das cargas horárias, principalmente nos cursos de licenciatura das instituições de ensino particulares, falta tempo hábil para que se vivenciem as transformações necessárias. 
Mas, se a articulação entre conteúdos e metodologias nos cursos de Licenciatura em Matemática encontra obstáculos mesmo após a publicação das diretrizes divulgadas pelo Conselho Nacional de Educação do MEC que citamos anteriormente, o que dizer da sua ocorrência nos cursos cuja organização curricular é anterior à publicação das diretrizes? Simplesmente não havia articulação. Como já é sabido, a maioria dos cursos de licenciatura brasileiros tinha duração de quatro anos, sendo destes, três voltados para o estudo do conteúdo específico e um voltado para o estudo das chamadas disciplinas pedagógicas, características que Borba (2010) nomeia modelo 3+1. As disciplinas do primeiro grupo eram oferecidas pelos institutos e departamentos de Matemática e as do segundo grupo pelas faculdades de educação. No caso dos cursos de Licenciatura em Matemática, boa parte dos professores dos três primeiros anos eram bacharéis e engenheiros e boa parte dos professores da formação pedagógica eram pedagogos, psicólogos, filósofos. Os conteúdos matemáticos eram ensinados sem que houvesse qualquer alusão ao seu ensino nos níveis Fundamental e Médio. Na verdade, não havia o debate sobre a distinção entre a matemática científica e a matemática escolar, que Borba (2010) aponta como elemento presente nas atuais pesquisas sobre formação de professores de Matemática, que, por sua vez, influenciaram, ainda que minimamente, a reestruturação de muitos cursos de licenciatura na última década.

Já as disciplinas pedagógicas eram abordadas em termos gerais sem que os licenciandos se ativessem às aplicações daquilo que estudavam à sua atuação profissional futura. No que diz respeito às disciplinas relacionadas à Psicologia, tema central deste artigo, havia certa ênfase na Psicologia do Desenvolvimento, na Psicologia Escolar e na Psicologia da Aprendizagem sem, contudo, ter ocorrido a mudança citada por Falcão (2003) “da aprendizagem no infinitivo para a aprendizagem de alguma coisa, ou seja, a psicologia da aprendizagem de conteúdos específicos: matemática, física, química, linguagem, conceitos ético-morais,ciências sociais etc (p. 17). Em resumo, nos cursos de Licenciatura em Matemática categorizados no modelo $3+1$ não se discutiam aspectos e contribuições da Psicologia da Educação Matemática que, segundo Falcão (2003) "é um domínio recente de pesquisa, reflexão teórica e aplicação prática, tendo como foco de análise a atividade matemática” (p.15).

Um exemplo disso pudemos verificar no depoimento de um aluno do Mestrado Profissional em Educação Matemática da Universidade Severino Sombra (USS), 
formado há cerca de 20 anos num curso de licenciatura com este perfil. Em sua fala, o aluno demonstrou desconhecer as pesquisas realizadas por Piaget para compreensão do processo de construção do raciocínio lógico-matemático pelas crianças e ainda a importância que ele atribui à aprendizagem matemática para o desenvolvimento deste raciocínio. Para o aluno, a teoria piagetiana se restringia às noções de esquema, acomodação, assimilação e às fases do desenvolvimento tão bem assinaladas por Piaget. Ele não percebia sequer as implicações desta teoria na fundamentação de uma proposta de ensino que privilegia a resolução de problemas. Descrevendo suas aulas de Psicologia da Educação quando era aluno no curso de licenciatura, o aluno expôs também que não se abordavam as contribuições que os conhecimentos da Psicologia poderiam oferecer ao processo de ensino e aprendizagem da Matemática especificamente, ou seja, estudava-se a Psicologia em linhas gerais, sem se avaliar seu potencial para compreensão do processo de aprendizagem da Matemática e para o desenvolvimento de estratégias de ensino e de materiais de apoio ao ensino. Além disso, sua turma era composta por alunos oriundos das mais variadas licenciaturas (Licenciatura em Química, Física, Biologia, História, Geografia etc.), o que tornava praticamente impossível articular a Matemática, a Psicologia e a Educação Matemática.

Casos como o que acabamos de descrever não são raros na turma de Mestrado Profissional em Educação Matemática da USS onde realizamos as atividades que descrevemos e analisamos neste artigo. Antes do início das aulas, fizemos uma análise do currículo e do histórico escolar de graduação dos alunos inscritos na disciplina e verificamos que, dos onze alunos inscritos, nove são ex-alunos de cursos com características do modelo $3+1$. E, em depoimento individual na primeira aula, os demais, que concluíram a licenciatura nos últimos cinco anos, declararam que também tiveram acesso apenas a conhecimentos gerais da Psicologia e não estudaram a Psicologia da Educação Matemática, embora seus cursos houvessem sido reformulados recentemente. Conhecedores destes fatos, ainda lhes pedimos que descrevessem os cursos de formação continuada que frequentaram depois que concluíram a graduação e haviam citado em seus currículos. Tínhamos esperanças de que, em algum momento da formação continuada, esta carência tivesse sido suprida, entretanto os depoimentos dos alunos explicitam que boa parte dos cursos ainda privilegia a matemática acadêmica como se o aprofundamento dos conhecimentos acadêmicos fosse suficiente para que o professor enfrentasse os problemas que se colocam no dia a dia da sala de aula. 
Moreira e David (2010) acrescentam que, nesta perspectiva:

O saber docente é decomposto em componentes, de tal forma que um deles, o chamado conhecimento da disciplina assume a condição de essencial. Os demais componentes, ainda que reconhecidos como saberes complexos e importantes, conformam um conjunto de conhecimentos de caráter basicamente acessório ao processo de transmissão do saber disciplinar. (p. 15)

Assim, percebemos que uma das questões centrais a serem discutidas numa disciplina voltada para as disciplinas cognitivas era a relevância dos conhecimentos da Psicologia da Educação Matemática para a atuação do professor e do pesquisador, ou seja, além dos conceitos chave de certas teorias cognitivas, é necessário promover a reflexão sobre suas aplicações no ensino e aprendizagem da Matemática em todos os níveis (Educação Infantil, Fundamental, Médio e Superior). Esta constatação foi decisiva para que criássemos no curso de Mestrado Profissional em Educação Matemática a disciplina Teorias de Aprendizagem, delineássemos seus objetivos e o método de ensino que adotaríamos.

\section{JUSTIFICATIVAS E OBJETIVOS DA DISCIPLINA}

O programa de mestrado em Educação Matemática da USS teve início no ano de 2008. Até o presente momento já foram defendidas 38 dissertações e realizados projetos, que se subdividiram entre as linhas de pesquisa Organização curricular em matemática e formação de professores e Metodologias e tecnologias de informação aplicadas ao ensino de matemática. Ele destina-se à formação de profissionais na área de concentração de Educação Matemática e tem por objetivo proporcionar uma formação científica ampla e aprofundada, capaz de produzir conhecimentos, difundi-los em universidades e, principalmente, aplicá-los em instituições de ensino, visando uma maior qualificação das atividades de magistério. Como está sintetizado no projeto do curso (2008), "o objetivo geral é propiciar reflexão sobre o campo da educação, valorizando os processos de ensino-aprendizagem de matemática" (Caracterização do curso, p. 1).

Ao abordar o perfil do professor que precisará formar, este Programa de Mestrado em Educação Matemática destaca a necessidade de outros conhecimentos, além dos conhecimentos matemáticos. Entre eles, aqueles advindos da sociologia, da antropologia, da educação e da psicologia, o que podemos perceber facilmente pelas 
disciplinas que compõem sua matriz curricular. Acredita-se que a integração destes conhecimentos aos conhecimentos matemáticos contribui decisivamente para a formação de um professor capaz de identificar e, sobretudo, utilizar a pesquisa de modo a agregar valor às suas atividades de prática docente, tornando-se professor-pesquisador.

Sendo assim, a concepção que orientou a construção do Programa e sobre a qual também fundamentamos a criação da disciplina Teorias de Aprendizagem vai ao encontro de Brito (2002), quando ela afirma que "a Psicologia Educacional apresentase juntamente com a Filosofia e a Sociologia, como um dos fundamentos da Educação Matemática e, como tal, comparece obrigatoriamente nos cursos de formação de professores" (p. 57).

Cabe ressaltar, porém, que a obrigatoriedade mencionada por Brito (2002) não se refere aos aspectos legais, que, inclusive, desapareceram com a nova legislação e a modernização dos cursos. Como esta autora (2002) acrescenta:

Trata-se da obrigatoriedade expressa pela estreita relação entre o desenvolvimento e a aprendizagem do indivíduo e a aquisição, manutenção e uso do conhecimento matemático, adquirido tanto dentro como fora do contexto escolar. A Psicologia deve estar inserida no contexto maior dos cursos de formação de professores, buscando trabalhar de forma mais próxima às demais disciplinas. (p. 57)

Podemos esclarecer esta afirmação tomando como exemplo nossas pesquisas anteriores em que foram descritos e analisados à luz da Psicologia Sócio-Histórica (Barbosa, 2002) e à luz da Teoria dos Campos Conceituais (Barbosa, 2008) os processos de construção de conceitos associados ao Teorema Fundamental da Aritmética (TFA) por alunos de sexto ano do Ensino Fundamental. Nossos conhecimentos matemáticos foram necessários para a identificação de conceitos e propriedades matemáticas inerentes ao TFA que são essenciais em seu estudo. Entretanto, mais do que identificar o que ensinar, foi necessário adequar as situações problema ao nível de entendimento das crianças, compreender e analisar os erros cometidos por elas e elaborar argumentos e representações que favorecessem a superação dos mesmos. Estas ações, fundamentais para que os estudantes adquirissem os conceitos matemáticos em questão e os usassem dentro e fora do contexto escolar, só nos foram possíveis porque buscávamos e empregávamos fundamentos das teorias cognitivas que havíamos escolhido. Em resumo, criando e analisando atividades com 
base nas teorias cognitivas, contribuíamos para que os estudantes avançassem no processo de construção do pensamento, ou seja, desenvolvessem seus potenciais de pensamento.

Sendo assim, concordamos com Brito (2002) quando, ao se referir às ideias de Sternberg e Spear-Swerling (1985), afirma que o objetivo principal da Psicologia Educacional deveria ser "levar os professores em formação a conhecer e compreender os diferentes tipos de pensamento e possibilitar que apliquem esse entendimento diretamente ao ensino”. (p. 59)

E legitimamos, apenas estendendo ao caso da formação continuada do professor, os objetivos gerais identificados por esta mesma autora (2002) para a abordagem da Psicologia Educacional nos cursos de formação de professores de conteúdos específicos (no presente caso, professores de Matemática). São eles:

1) Preparar profissionais para o ensino na área de Educação Matemática, com vistas à integração entre o conteúdo da disciplina e as maneiras de trabalhar esse conteúdo.

2) Discutir e propor soluções, baseadas em pesquisas relevantes na área, para os problemas e dificuldades que ocorrem comumente na aprendizagem-ensino da Matemática escolar.

3) Promover e estimular a atividade interdisciplinar em Educação Matemática com a participação dos diferentes profissionais envolvidos nessa área.

4) Buscar uma compreensão melhor e mais aprofundada dos diferentes aspectos psicológicos do ensino e a aprendizagem da Matemática e as implicações desses estudos.

5) Fundamentar, a partir de uma perspectiva histórica e psicológica, as diferentes crenças, concepções e atitudes em relação à Matemática e à aprendizagem dessa disciplina, relacionando-os aos aspectos cognitivos e afetivos.

6) Possibilitar que os futuros professores entendam os vários tipos de pensamento, aplicando esse entendimento diretamente à instrução.

7) Formar o professor para ser um pesquisador em sala de aula. Isso implica dar condições, ao futuro professor, para que ele questione, de maneira investigativa, os acontecimentos do espaço escolar, e seja capaz de buscar recursos na literatura pertinente, na própria experiência e na de outros, tentando apresentar alternativas de solução adequadas à realidade dos estudantes e ao contexto escolar. (p. 60)

E, por fim, ainda influenciados pelas ideias de Brito (2002), nossos objetivos na disciplina Teorias de Aprendizagem passaram a ser:

- Identificar as principais ideias e conceitos chave das teorias cognitivas de Piaget, Vygotsky e Vergnaud;

- Reconhecer pontos em comum entre as teorias; 
- Reconhecer aspectos de divergência entre as teorias;

- Analisar pesquisas na área da Educação Matemática que utilizam estas teorias cognitivas como quadro teórico;

- Discutir sobre a importância das teorias cognitivas para as pesquisas em Educação Matemática;

- Discutir sobre a importância dos conhecimentos provenientes das teorias cognitivas para a atuação do professor de Matemática;

- Utilizar as teorias cognitivas para interpretação de uma situação de sala de aula real.

A partir desse conjunto de objetivos, definimos nossa metodologia de ensino. Como explicamos nos próximos itens, procuramos empregar metodologias coerentes com as teorias cognitivas a serem estudadas.

\section{A EXPERIÊNCIA}

Nossa pesquisa teve por objetivo desenvolver e analisar uma sequência de atividades que favorecessem a construção dos principais conceitos associados a três teorias cognitivas - o Construtivismo de Piaget, a Psicologia Sócio-histórica de Vygotsky e a Teoria dos Campos Conceituais (TCC) de Vergnaud - por alunos do Mestrado Profissional em Educação Matemática da USS. Cabe lembrar que incluímos no que chamamos de construção dos principais conceitos, suas articulações com a Educação Matemática, cuja importância defendemos fundamentados em Brito (2002) e Resnick e Ford (1981). A pesquisa se desenvolveu ao longo do primeiro semestre de 2011 durante as aulas da disciplina Teorias de Aprendizagem, oferecida como eletiva para os alunos do mestrado com carga horária de 60 horas. Como estávamos realizando uma pesquisa e, simultaneamente, uma intervenção de ensino, podemos afirmar que utilizamos o método da pesquisa-ação. Nesse método, investigação e prática pedagógica caminham juntas: "O pesquisador se introduz no ambiente a ser estudado não para observá-lo, mas, sobretudo, para mudá-lo” (Fiorentini, 2004, p.69). 
Havia na turma onze alunos: cinco alunos que cursavam o primeiro período, cinco que cursavam o terceiro período e um que era aluno especial, não tendo ainda matrícula como aluno oficial do programa. Foram questões que nortearam nossas investigações: Por que os indivíduos pesquisados resolveram estudar Teorias de Aprendizagem? Quais foram suas experiências prévias com as teorias cognitivas? Conseguem identificar as potencialidades destas teorias no que se relaciona à melhoria do processo de ensino aprendizagem da Matemática em todos os níveis? De que modo o conhecimento destas teorias contribui para a formação de um pesquisador em Educação Matemática?

Começamos as atividades com diálogos e debates em que os alunos relatavam suas experiências de estudos de Psicologia no curso de Licenciatura em Matemática e seus conhecimentos prévios sobre as teorias cognitivas que seriam abordadas na disciplina. Percebemos, como já exemplificamos, que a formação inicial que o grupo teve em relação ao tema havia sido insuficiente: conhecimento teórico bastante superficial, sendo, em especial, a Teoria dos Campos Conceituais totalmente desconhecida do grupo, e nenhuma integração das teorias ao processo de construção de conceitos matemáticos.

Não foi tarefa simples suprir esta carência e, além disso, contribuir significativamente para a formação de pesquisadores em Educação Matemática, dado que nosso público alvo não eram alunos da licenciatura e sim, do mestrado profissional. Pensando nisso, utilizamos na disciplina, entre outras, as seguintes atividades didáticas: i) Leitura de pesquisas na área da Educação Matemática que se remetiam às teorias cognitivas em questão em seus quadros teóricos; ii) Leitura de textos de Vergnaud, Vygotsky, Piaget e alguns de seus discípulos; iii) Resolução e análise de problemas matemáticos em que se visava não só as diferentes soluções, mas o reconhecimento de suas potencialidades de ensino com base nas teorias de Piaget, Vygotsky e Vergnaud; e iv) realização de uma pesquisa de campo com alunos dos ensinos Fundamental e Médio.

Neste artigo analisamos uma atividade que se enquadra no item iii. Descrevemos e refletimos sobre a resolução e análise à luz da TCC de uma situação problema envolvendo o conceito de função afim realizada com todo o grupo pesquisado. Escolhemos discutir tal atividade porque, por meio dela, pudemos verificar de maneira 
mais objetiva o processo de transformação das concepções do grupo em relação às teorias cognitivas e suas implicações à Educação Matemática.

\section{RESOLUÇÃO E ANÁLISE DA SITUAÇÃO PROBLEMA}

Neste item são apresentados os principais resultados da parte da pesquisa referente à resolução de problemas relacionados ao tema função afim. Para maior clareza, começo oferecendo uma visão geral do que ocorreu. Depois explico como o debate sobre a solução de um problema matemático extraído de Lima et all (2001) contribuiu para a construção das principais ideias associadas à Teoria dos Campos Conceituais, que, segundo Vergnaud (1990), são as ideias de situação, esquema, invariantes operatórios, conceito, o papel das representações no processo de construção de um conceito e a própria noção de campo conceitual.

Já nas primeiras aulas, com a apresentação e reflexão sobre a ementa, os alunos perceberam que naquela disciplina estudariam as teorias cognitivas de um jeito diferente. Durante esta apresentação discutimos sobre as principais dificuldades enfrentadas por alunos do Ensino Fundamental na construção de conceitos do campo aditivo e do campo multiplicativo e sobre as contribuições que as teorias a serem estudadas poderiam oferecer para a identificação das causas de tais dificuldades e para um ensino mais significativo das quatro operações. Em resumo, mesmo na apresentação da ementa, já procuramos integrar as teorias cognitivas e os conteúdos matemáticos.

Outro indício de que haveria muita novidade pela frente foi a forma de organização do trabalho pedagógico. Desde o início foi solicitado aos alunos que formassem trios. Foi-lhes dito, nesta ocasião, que a maioria das aulas transcorreria assim e que, de períodos em períodos, eles teriam a oportunidade de mudar de trio se o desejassem. Quando não estavam trabalhando em trios, os alunos formavam com suas carteiras um grande círculo do qual também fazíamos parte. Ao longo do semestre, em trios, os alunos faziam a leitura da parte teórica e resolviam os problemas dos capítulos 1, 2 e 3 do livro Temas e Problemas, que trataram de adquirir logo. No grande círculo, faziam a leitura reflexiva de pesquisas fundamentadas nas teorias cognitivas elencadas na ementa, apresentavam as suas soluções para os problemas matemáticos trabalhados em trio e analisavam-nas à luz das teorias cognitivas. Tinham à disposição uma lousa, que, inclusive, fizeram bastante uso para apresentarem suas soluções. 
Ministrando a disciplina, cuidamos para não nos colocarmos como detentores de um saber absoluto, colocávamos, a todo momento, os nossos conhecimentos à prova, confrontávamos as teorias cognitivas com os conhecimentos matemáticos e com as experiências profissionais dos que estavam presentes na sala de aula, uma vez que todos atuam ou já atuaram como professores de Matemática dos ensinos Fundamental e Médio das redes pública e privada dos estados do Rio de Janeiro e de Minas Gerais. Desta forma, procuramos fundamentar nossas ações pedagógicas em princípios que são consensuais entre as três teorias cognitivas enfatizadas na disciplina: as noções de que i) o conhecimento é algo a ser construído pelo aluno e não dado a priori pelo professor; ii) cabe ao professor a função de mediar este processo e iii) o uso diversificado da linguagem favorece a construção de conceitos.

A intervenção se dava mediante registro de campo escrito das reações e dos comportamentos mais gerais dos alunos, bem como de nossa atuação. Esses procedimentos, aliados a um estado de atenção constante e consequente registro de situações fortuitas como, por exemplo, os diálogos ocorridos entre os alunos ou as vezes que nos procuravam, antes do início das aulas ou durante os intervalos, relatando suas experiências profissionais e pessoais, solicitando algum tipo de aconselhamento, também nos ajudaram a compreender os conhecimentos que estavam construindo sobre as teorias cognitivas e a importância que atribuíam a eles.

Mais especificamente, a pesquisa concretizou-se da seguinte forma: realizávamos a intervenção numa aula, logo em seguida, fazíamos o registro escrito, durante a semana seguinte, analisávamos os registros, fazíamos os ajustes necessários na intervenção com base na análise dos mesmos e o processo recomeçava a cada nova aula.

Escolhemos abordar as teorias de Piaget, Vygotsky e Vergnaud pelo fato de estarem entre as mais empregadas nas pesquisas nacionais e internacionais em Educação Matemática que visam à descrição e análise dos processos de construção de conceitos. Os conceitos matemáticos cujos processos de construção foram alvo de análise à luz destas teorias, durante as aulas, são funções afins, funções quadráticas e funções exponenciais. Neste caso, justificamos nossa escolha pela riqueza de representações que podem ser usadas no seu estudo, pelo fato de serem assuntos que permitem certa articulação entre conhecimentos algébricos e geométricos e também por 
serem conhecimentos indispensáveis no estudo de Análise Matemática, disciplina obrigatória do nosso Programa de Mestrado e que dez dos onze alunos da turma ainda teriam que cursar.

No estudo das funções afins, o problema a seguir, extraído de Lima et al (2003) permitiu uma discussão mais aprofundada sobre a Teoria dos Campos Conceituais:

Na loja A, um aparelho custa 3800 reais mais uma taxa real de manutenção de 20 reais. $\mathrm{Na}$ loja B, o mesmo aparelho custa 2500 reais porém a taxa de manutenção é de 50 reais por mês. Qual das duas opções é a mais vantajosa? (p.19)

Todos os alunos responderam satisfatoriamente ao problema. Alguns chegaram a descrever mais de uma solução e foi possível distribuir as soluções que apresentaram em quatro categorias. Na primeira categoria, que designamos solução canônica, por ser o tipo de solução oferecido com mais frequência nos livros didáticos do Ensino Médio, os alunos modelaram a situação de cada loja por uma função afim, por exemplo, para a loja $\mathrm{A}$, escreveram a lei $\mathrm{A}(\mathrm{x})=3800+20 \mathrm{x}$, que associa o custo $\mathrm{A}(\mathrm{x})$ ao número $\mathrm{x}$ de meses e, para a loja $\mathrm{B}$, escreveram a lei $\mathrm{B}(\mathrm{x})=2500+50 \mathrm{x}$, que associa o custo $\mathrm{B}(\mathrm{x})$ ao número $\mathrm{x}$ de meses. Em seguida, fizeram o estudo do sinal de cada uma, identificando a partir de quantos meses o custo da loja B ultrapassa o custo da loja A.

A segunda categoria designamos solução gráfica. Nela, dispondo de papel quadriculado, os alunos construíram num mesmo gráfico duas retas: uma que descreve o crescimento do custo da loja A e outra que descreve o crescimento do custo da loja B conforme os meses vão se seguindo. Com base na observação das retas, concluíram que, há um número de meses em que o custo é o mesmo nas duas lojas e que, para qualquer número de meses superior a ele, o custo na loja B seria superior ao da loja A.

A terceira e a quarta categorias não envolveram diretamente o conceito de função afim. Na terceira, por exemplo, houve o emprego dos conhecimentos de proporcionalidade e por isso a designamos de solução por regra de três. Os alunos perceberam que, a cada mês, a diferença entre o custo da loja A e o custo da loja B diminuía em trinta reais, e, então, utilizando uma regra de três simples, procuravam descobrir em quantos meses esta diferença diminuiria mil e trezentos reais, dado que esta era a diferença entre os custos fixos de cada loja. Já a quarta, chamada de solução pela tabela, consistia em apenas tabelar mês a mês o custo de cada loja e observar que, 
a partir de certa linha da tabela, o custo da loja B se tornaria maior que o da loja A e, assim, para obter a resposta do problema, bastaria contar o número de linhas da tabela.

O ponto inicial para análise desta situação problema com base na Teoria dos Campos Conceituais foi a comparação das quatro categorias de solução. Questionamos os alunos sobre os conceitos matemáticos mobilizados nas soluções de cada categoria e eles identificaram expressões algébricas, equação e inequação do primeiro grau, leitura e construção de gráficos e tabelas, razões e proporções, regra de três, progressão aritmética, variável livre, variável dependente, função afim, coeficiente angular e coeficiente linear. Coerentemente com a Teoria dos Campos Conceituais, eles puderam compreender que não é possível construir um conceito isoladamente (Vergnaud, 1990). A compreensão de um conceito está imbricada à compreensão de outros conceitos e, portanto, não faz sentido para o professor planejar uma aula sobre um conceito apenas e sim, sobre o campo conceitual em que ele está inserido.

Uma vez construída a noção de campo conceitual, partimos para a exploração do papel que Vergnaud atribui às representações no processo de construção do conceito. Segundo Vergnaud (1990):

Não se debate a verdade ou a falsidade de um enunciado totalmente implícito, nem se identificam os aspectos do real aos quais se tem de prestar atenção, sem o auxílio de palavras, de enunciados, de símbolos e de signos. A utilização das representações é indispensável à conceitualização. (p. 166)

Neste caso, solicitamos aos alunos que voltassem suas atenções para os recursos que utilizaram para solucionar a questão e para comunicar suas soluções. Cabe mencionar a dificuldade de alguns deles para compreenderem o que são representações. Em comentários que fizeram durante a aula, os alunos declararam que, para eles, as representações eram o próprio conceito ou o próprio real e nunca haviam pensado na possibilidade de elas serem um dos componentes do conceito e de terem uma função no seu processo de construção.

Com muito empenho, reconheceram que durante a resolução do problema ou na exposição de suas soluções, utilizaram-se da língua materna, da linguagem algébrica, da linguagem geométrica (desenhos de retas e inclinações), dos gestos, dos gráficos e das tabelas. Refletiram sobre o esforço de se fazer entender pelo grupo que assistia à 
apresentação de suas soluções. Nas palavras de uma aluna: "para expressar com clareza o que havia pensado, eu usei várias linguagens e esse uso me permitia compreender ainda mais a situação e a matemática que havia nela”. Em resumo, concluíram que, para compreenderem a situação problema e para comunicarem ao grupo suas soluções, utilizaram-se de linguagens variadas. A escolha e a coordenação destas linguagens bem como a possibilidade de transitar de uma a outra, permitiramlhes avançar na construção dos conceitos em questão, pois facilitavam a observação de regularidades e padrões numéricos.

Em linhas gerais, de acordo com as conclusões a que os alunos chegaram durante as reflexões que descrevemos, podemos dizer que, nas aulas de Teorias de Aprendizagem, prática e teoria entrelaçaram-se em intensidade e ritmos variados, mas nunca se distanciaram completamente. Quando não analisavam os próprios procedimentos para lidar com a situação, ou seja, seus próprios processos de aprendizagem, os alunos buscavam exemplos de suas vivências profissionais: todos já haviam em algum momento profissional ensinado funções afins em turmas de Ensino Médio. Inferimos, então, que nossa prática se aproximava do que Brito (2002) sugeriu. Nas atividades da disciplina, os alunos começavam a compreender como a informação matemática é processada e retida, como diferentes habilidades podem ser desenvolvidas.

Finda a fase de identificação do campo conceitual em que as funções afins estão inseridas e do reconhecimento do papel das representações na conceitualização, conduzimos as discussões para a identificação dos esquemas empregados pelos alunos para lidar com a situação, dos invariantes operatórios que os compõem e para a possibilidade de classificar situações. Conforme já mencionamos, estes são conceitos essenciais na Teoria dos Campos Conceituais.

Como para Vergnaud (1990, p. 157), esquema é "a organização invariante da conduta para uma dada classe de situações", inicialmente pedimos aos alunos que descrevessem suas condutas para resolver a situação proposta. Em seguida, solicitamos que, mudando o enredo, criassem problemas cujas soluções requeressem as mesmas condutas, o que preferiam nomear de o mesmo raciocínio. Alguns alunos criaram, outros relembraram problemas que são propostos nos livros didáticos que adotam nas classes de Ensino Médio em que lecionam. Nesta análise dos vários problemas em que, para solucioná-los, empregam-se os mesmos raciocínios ou as mesmas condutas, o que 
na TCC significa afirmar que mobilizam os mesmos esquemas, os alunos compreenderam a necessidade de se classificar situações. Além disso, refletiram sobre suas atuações profissionais, comentando que "um bom professor, ao ensinar um assunto, deve propor problemas que envolvam o assunto e que pertençam a diferentes classes de situações".

No comentário do aluno, podemos observar o avanço na construção do conceito de conceito de acordo com a TCC. Se inicialmente, os alunos acreditavam que a representação era em si o conceito, por meio da reflexão sobre as classes de situações e sobre os esquemas, eles também passaram a associar o conceito às situações que lhe conferem significado e aos invariantes operatórios, que são os conhecimentos constituintes dos esquemas mobilizados pelo indivíduo para lidar com a classe de situações. Assim, aproximavam suas concepções de conceito da definição dada por Vergnaud (1990):

(...) um conceito é um trigémio de três conjuntos:

$\mathrm{C}=(\mathrm{S}, \mathrm{I}, \mathrm{s})$

S: conjunto das situações que dão sentido ao conceito (a referência);

I: conjunto das invariantes nas quais assenta a operacionalidade dos esquemas (o significado);

s: conjunto das formas pertencentes e não pertencentes à linguagem que permitem representar simbolicamente o conceito, as suas propriedades, as situações e os procedimentos de tratamento (o significante). (p. 166)

Desta forma, mais uma vez constatamos que é possível o estudo da Psicologia da Educação tal como recomendado por Brito (2002) e Falcão (2003). Além de abordar o conteúdo específico (funções afins) e os conteúdos pedagógicos (teorias cognitivas), articulamos as duas áreas e rompemos com a concepção que inspirou o modelo $3+1$ nos cursos de Licenciatura durante décadas. Com base nas suas experiências profissionais e na análise dos próprios processos mentais e de aprendizagem, insistimos na discussão com os alunos sobre processos de pensamento, pois acreditamos que, com estes conhecimentos, o professor poderá criar condições para que os estudantes desenvolvam seus potenciais de pensamento. E, quando usamos a expressão criar condições, estamos nos referindo ao desenvolvimento por parte do professor de uma postura de pesquisador do processo de ensino-aprendizagem. Afinal, para criar tais 
condições, é preciso identificar problemas relativos à aprendizagem tanto num grupo de alunos quanto individualmente, levantar hipóteses para solucioná-los, analisando-os à luz das teorias cognitivas.

\section{CONSIDERAÇÕES FINAIS}

Neste artigo, tivemos a pretensão de apontar caminhos para o ensino das teorias cognitivas em cursos de Mestrado Profissional em Educação Matemática. Buscamos nas pesquisas de Brito (2002), Falcão (2003) e Moreira e Davi (2010) argumentos que justificassem os procedimentos que empregamos em nossa pesquisa de campo com mestrandos que cursavam a disciplina Teorias de Aprendizagem. A experiência descrita é apenas parte de uma sequencia de atividades muito mais ampla que visa o ensino das teorias cognitivas e, por isso, não nos permite fazer generalizações ou afirmações contundentes. Entretanto alguns aspectos que se mostraram satisfatórios podem enriquecer o debate sobre as metodologias de ensino da Psicologia nos cursos de formação inicial e continuada de professores. Procuramos em todos os momentos integrar conhecimentos matemáticos e conhecimentos das teorias cognitivas, incentivamos a análise de circunstâncias que são vividas diariamente nas aulas de Matemática dos ensinos Fundamental e Médio. Além disso, recorremos à metacognição, ou seja, incentivamos os indivíduos a refletirem sobre seus processos mentais e de aprendizagem.

\section{BIBLIOGRAFIA}

BARBOSA, Gabriela dos Santos. Construção dos Conceitos de Múltiplo e Divisor à Luz da Psicologia de Vygotsky. (Dissertação de Mestrado). Universidade Santa Úrsula, Rio de Janeiro; 2002.

, O Teorema Fundamental da Aritmética: Jogos e Problemas com Alunos do Sexto Ano do Ensino Fundamental. (Tese de Doutorado). PUC, São Paulo; 2008.

BORBA, Marcelo de Carvalho. Tendências internacionais em formação de professores de Matemática. São Paulo: Autêntica, 2010.

BRASIL, Diretrizes Curriculares para Cursos de Licenciatura em Matemática. MEC, CNE/CP, 19 de 1999.

BRITO, Maria Regina Ferreira. A Psicologia Educacional e a formação do Professorpesquisador: criando situações desafiadoras para a aprendizagem e o ensino da 
Matemática. Revista da Sociedade Brasileira de Educação Matemática, ano 9, n 11A, p. 57-67. Abril, 2002.

FALCÃO, Jorge Tarcísio da R. Psicologia da Educação Matemática: uma introdução. Belo Horizonte: Autêntica, 2003.

FIORENTINI, Dario. Pesquisar práticas colaborativas ou pesquisar colaborativamente? In: BORBA, Marcelo de Carvalho; ARAÚJO, Jussara de Loiola (Orgs.). Pesquisa qualitativa em Educação Matemática. Belo Horizonte: Autêntica, 2004.

LIMA, Elon Lages; MORGADO, Augusto César; WAGNER, Eduardo, CARVALHO, Paulo César Pinto de. Temas e Problemas. Rio de Janeiro: SBM, 2003.

MOREIRA, Plínio Cavalcanti; DAVID, Maria Manuela M. S. A formação matemática do professor: licenciatura e prática docente escolar. $2^{\mathrm{a}}$ Edição. São Paulo: Autêntica, 2010.

RESNICK, Lauren B; FORD, Wendy W. The Psycology of Mathematics for instruction. Hillsdale, New Jersey: Lawrence Erlbaum Associates, 1981.

STERNBERG, Louise; SPEAR-SWERLING, Robert J. Teaching of thinking. Washington, DC: American Psichological Association, 1985.

VERGNAUD, Gérard. La théorie des champs conceptuels. Recherches en Didactique des Mathématiques, v.10, n. 2-3, p. 133-170, 1990. 